\title{
SISTEM INFORMASI PEMESANAN RUANGAN MEETING BERBASIS WEB APP MENGUNAKAN FRAMEWORK CODEIGNITER PADA PT. BARATA INDONESIA - CILEGON, BANTEN
}

\author{
Khasan Asrori ${ }^{1}$, Ely Nuryani ${ }^{2}$ \\ ${ }^{1,2}$ Fakultas Ilmu Komputer Universita Banten Jaya \\ Jl. Syeh Nawawi Albantani, Curug, Kota Serang, Banten \\ Email: khasanasrori@gmail.com ${ }^{1}$, elynuryani@ unbaja.ac.id ${ }^{2}$
}

\begin{abstract}
Along with the development of the technology field at the company PT. Barata Indonesia, needs support to assist organizational activities, such as in ordering meeting rooms. Currently, information of meeting rooms availability and ordering at PT. Barata Indonesia still hasn't used technology so the process of ordering a meeting room is by contacting the room admin to ask about the availability of the place to be booked. This is less effective because the customer cannot know directly which room can be used for meetings and according to the capacity of the person. Therefore, this application is made to facilitate ordering meeting rooms at the company. The development of this meeting room reservation information system uses the SDLC Waterfall method which aims to simplify and speed up information access. The development of this Meeting Room Reservation Information System uses the CodeIgniter 3 Framework, which has 2 (two) interfaces, namely FrondEnd, which is the start page of the web application that is displayed for visitors and BackEnd is the admin page to process the required information data sources. The results of the system trial show that the application of the Meeting Room Booking Information System can provide more flexible information.
\end{abstract}

Keywords: CodeIgniter, Information Systems, Ordering, Web Applications.

\section{PENDAHULUAN}

Seiring berkembangnya perusahaan pada PT. Barata Indonesia, memerlukan dukungan untuk membantu kegiatan organisasi yaitu dalam pemesanan ruangan meeting. Karena dunia teknologi saat ini sudah semakin berkembang pesat, maka perusahaan mengikuti perkembangan teknologi agar lebih memudahkan pekerjaan karyawan salah satunya dalam pemesanan ruangan meeting ini karena sistem adalah sesuatu yang kompleks dan mencakup dimensi manusia sebagai pengguna dan mencakup berbagai disiplin ilmu (Yulia, Rahmat Fauzi, 2018) serta memiliki kecepatan yang tinggi dibandingkan dengan pengelolaan secara manual maka dari 
itu sistem informasi digunakan sebagai alat untuk membantu dalam menyelesaikan suatu pekerjaan agar lebih cepat.

Saat ini informasi dari ketersediaan ruangan meeting dan pemesanan dilakukan secara manual dengan menghubungi petugas ruangan meeting melalui telepon untuk menanyakan ruangan yang akan dipesan tersedia atau tidak. Hal ini kurang efektif karena pemesan tidak bisa mengetahui langsung ruangan mana saja yang dapat digunakan untuk meeting dan sesuai dengan kapasistas orang yang diinginkan, mengingat bahwa sistem dapat saling berkaitan dan saling terhubung untuk melakukan tugas bersama-sama (Yuli Mutiara, 2018). Maka dari itu dibuatnya aplikasi ini untuk memudahkan pemesanan ruangan meeting pada perusahaan.

Dari masalah tersebut maka dilakukannya penelitian yang berjudul pemesanan ruangan meeting berbasis website ini demi menjamin kelancaran penjadwalan ruangan meeting agar tidak bertabrakan dengan pemesan lainya dan diharapkan ruangan dapat digunakan dan berjalan dengan baik sesuai dengan kebutuhan dari pemesannya.

\section{METODE PENELITIAN}

Dalam perancangan sistem ini peneliti menggunakan metode observasi dan wawancara untuk mendapatkan informasi keadaan yang terjadi dengan cara menganalisa data secara fakta sesuai dengan apa yang penulis dapatkan dari hasil penelitian.

\section{Teknik Pengumpulan Data}

Ada berbagai teknik pengumpulan data yang dapat dilakukan dalam sebuah penelitian, dan pada penelitian ini peneliti melakukan teknik pengumpulan data sebagai berikut:

\section{Studi Kepustakaan}

Penulis memperoleh informasi yang berkaitan dengan judul yang menjadi obyek penelitian. Informasi didapatkan melalui buku, jurnal, karya ilmiah, internet dan sumber lain untuk dijadikanya referensi. 
2. Studi Lapangan

Dalam perancangan penelitian ini penulis melakukan beberapa studi lapangan sebagai berikut:

a. Observasi, proses pengamatan objek penelitian secara langsung di lapangan pada saat melakukan riset. penulis melakukan pengamatan langsung ke objek penelitianya untuk mendapatkan informasi yang terkait dengan kegiatan yang akan diamati untuk mengetahui kegiatan yang dilakukan secara langsung.

b. Wawancara, melakukan wawancara kepada petugas yang mengelola ruangan meeting untuk mengetahui hal-hal yang perlu diketahui dalam perancangan sistem ruangan meeting yang akan dibuat, dan cara untuk mengatur atau memesan ruangan meeting.

\section{Teknik Analisa Data}

Metode pengembangan yang digunakan oleh penulis dalam penelitian ini menggunakan metodologi System Development Life Cycle (SDLC) atau sering disebut sebagai pendekatan air terjun (waterfall) yang merupakan metodologi umum dalam pengembangan sebuah sistem. SDLC juga merupakan pola yang diambil untuk mengembangkan sistem, yang terdiri dari beberapa tahapantahapan: rencana (planning), analisis (analysis), desain (design), implementasi (implementation), pengkodean (coding), uji coba (testing), dan pemeliharaan (maintenance).

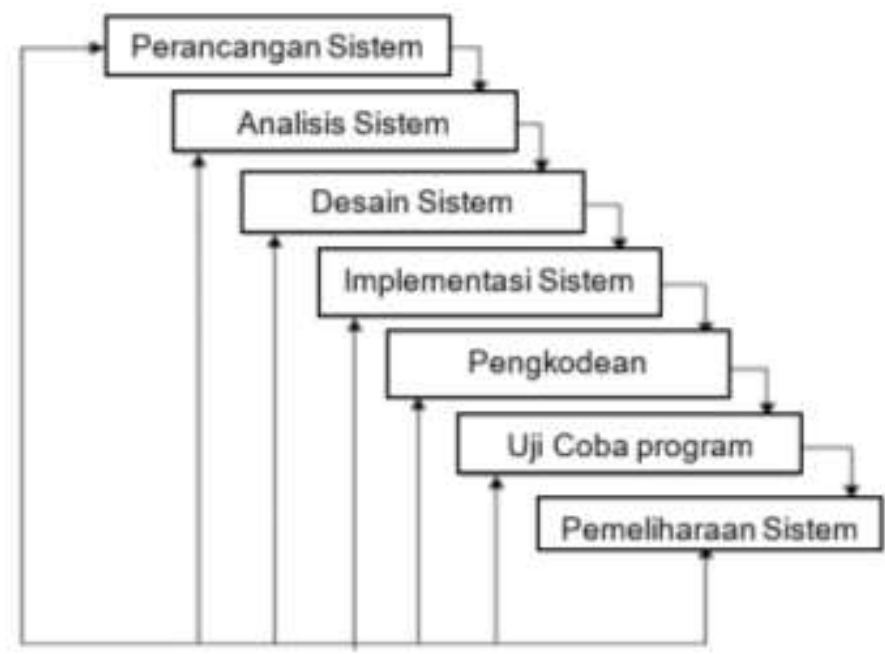

Gambar 1. Teknik analisa Data SDLC 


\section{HASIL DAN PEMBAHASA}

Pada kali ini penetili merancang dan mengelola data Pemesanan ruangan meeting pada PT. Barata Indonesia ini agar menjadi terkomputerisasi, mulai dari gambar flowmap usulan perancangan pelaksanaan, uraian flowmap, kelebihan perancangan usulan hingga uraian rancangan program aplikasi atau komputerisasi pelaksanaan Pemesanan ruangan meeting, yaitu sebagai berikut:

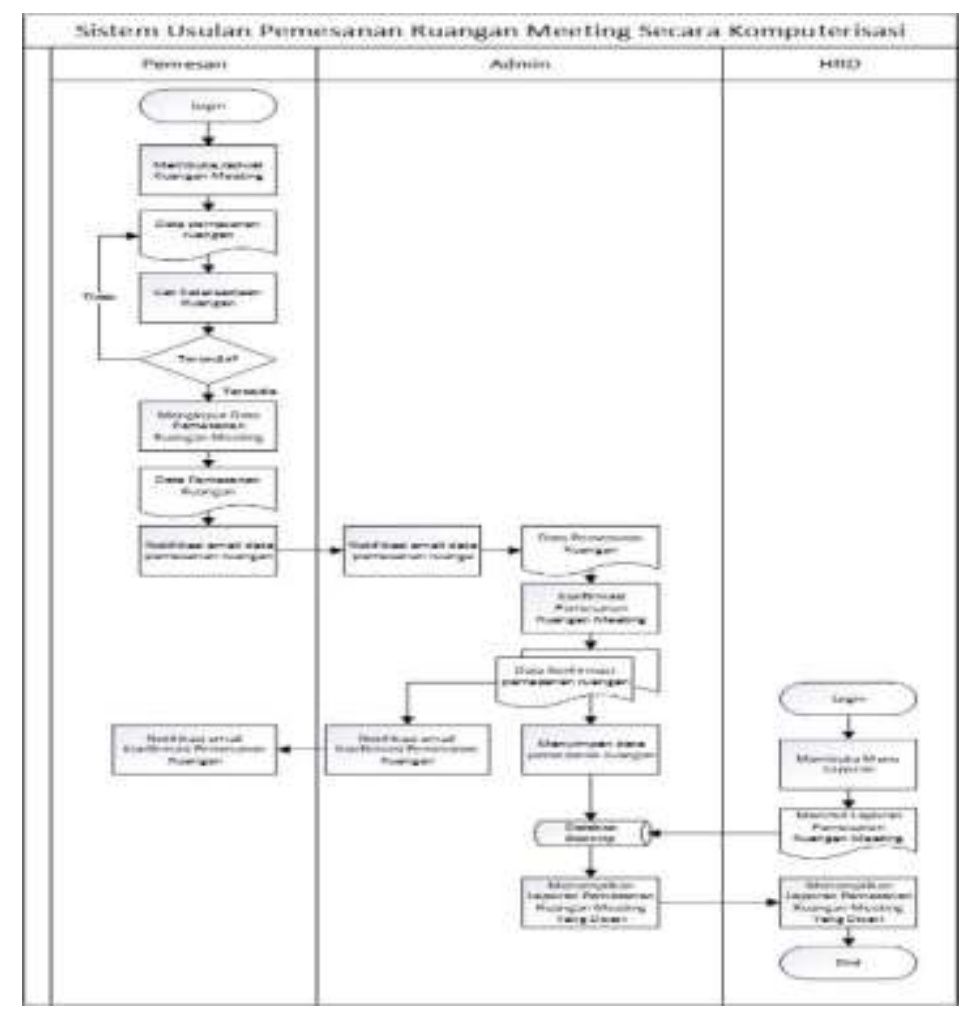

Gambar 2. Flow map sistem usulan

Peneliti menuraikan flowmap dari pelaksanaan sistem berjalan secara komputerisasi, sebagai berikut:

1. Pemesan login terlebih dahulu pada aplikasi pemesanan ruangan meeting

2. Pemesan memesan ruangan meeting yang diinginkan

3. Jika ruangan yang diinginkan pemesan tidak tersedia, pemesan mencari ruangan lain yang tersedia

4. Jika ruangan yang diinginkan pemesan tersedia, pemesan menginput ruangan tersebut

5. Sistem akan mengirim email pemesanan ruangan meeting kepada Admin untuk mengkonfirmasi pemesanan ruangan meeting 
6. Setelah admin mengkonfirmasi, pemesan akan mendapatkan notifikasi email konfirmasi pemesanan ruangan

7. Data pemesanan ruangan meeting yang sudah dipesan akan disimpan dalam database

8. Jika HRD membutuhkan laporan pemesanan ruangan meeting, HRD harus login terlebih dahulu ke dalam aplikasi pemesanan ruangan meeting, kemudian membuka menu laporan dan mencari laporan yang diinginkan, kemudian sistem akan menampilkan laporan yang dicari.

Uraian perancangan komputerisasi dalam pembuatan aplikasi pemesanan ruangan meeting dengan menggunakan UML dimulai dari Use Case Diagram, Class Diagram, Activity Diagram dan sequence Diagram.

\section{Use Case Diagram}

Use Case Diagram menjelaskan tentang kegiatan yang dapat dilakukan oleh setiap pengguna pada sistem yang sedang berjalan yaitu pemesanan ruangan meeting pada PT. Barata Indonesia yang dibagi menjadi tiga bagian yaitu Admin, User dan HRD, adalah sebagai berikut:

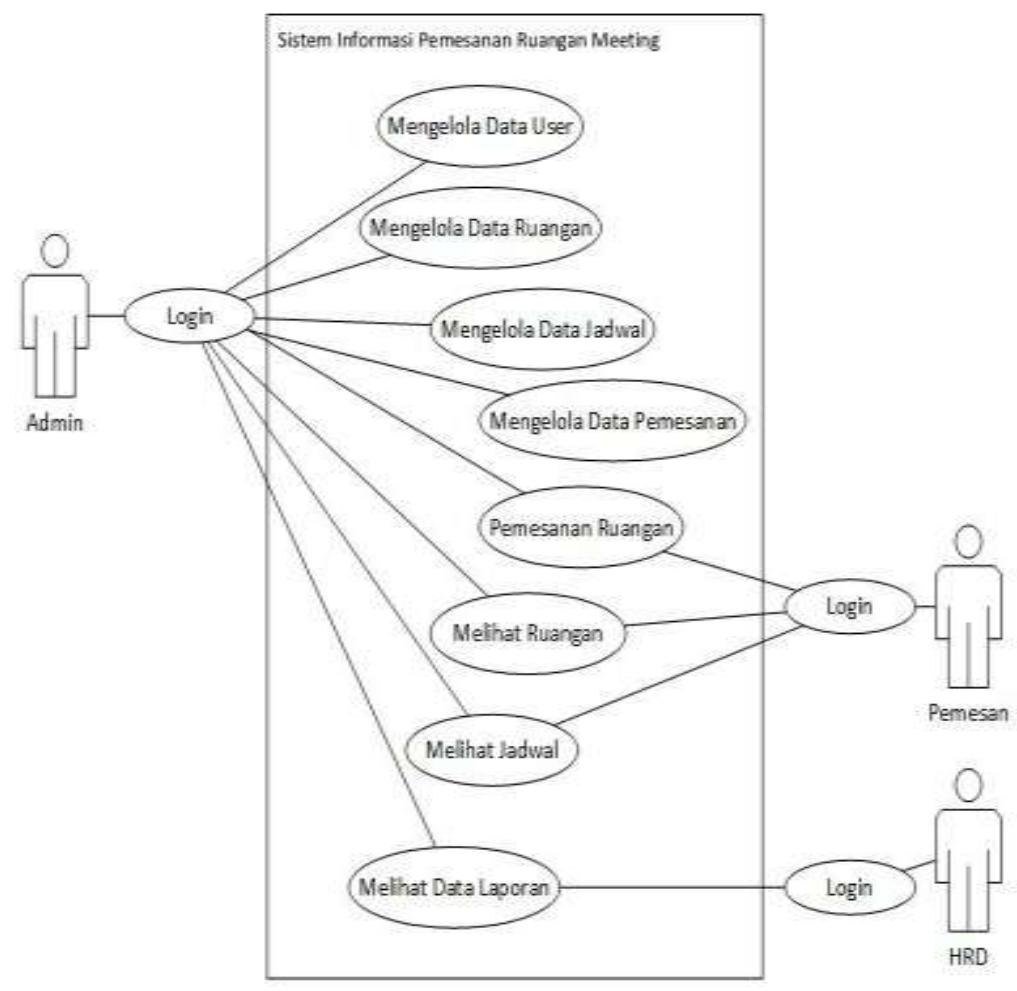

Gambar 3. Use Case Diagram 
Tabel 1. Penjelasan Use Case Diagram

\begin{tabular}{|c|c|c|c|c|}
\hline No & Nama Use Case & $\begin{array}{l}\text { Uraian use } \\
\text { case }\end{array}$ & $\begin{array}{c}\text { Data input dan } \\
\text { output }\end{array}$ & $\begin{array}{l}\text { Peran } \\
\text { Aktor }\end{array}$ \\
\hline 1 & $\begin{array}{l}\text { Mengelola Data } \\
\text { User }\end{array}$ & $\begin{array}{l}\text { Menambah, } \\
\text { Mengubah dan } \\
\text { Menghapus } \\
\text { Data User }\end{array}$ & $\begin{array}{l}\text { Input: Data User } \\
\text { Output: Data User }\end{array}$ & Admin \\
\hline 2 & $\begin{array}{l}\text { Mengelola Data } \\
\text { Ruangan }\end{array}$ & $\begin{array}{l}\text { Menambah, } \\
\text { mengubah, dan } \\
\text { menghapus } \\
\text { data ruangan }\end{array}$ & $\begin{array}{l}\text { Input: Data } \\
\text { Ruangan } \\
\text { Output: Data } \\
\text { Ruangan }\end{array}$ & Admin \\
\hline 3 & $\begin{array}{l}\text { Mengelola Dta } \\
\text { Jadwal }\end{array}$ & $\begin{array}{l}\text { Menambah, } \\
\text { mengubah, dan } \\
\text { menghapus } \\
\text { data jadwal }\end{array}$ & $\begin{array}{l}\text { Input: Data Jadwal, } \\
\text { ruangan, dan waktu } \\
\text { Output: Data } \\
\text { Jadwal }\end{array}$ & Admin \\
\hline 4 & $\begin{array}{l}\text { Mengelola Data } \\
\text { Pemesanan }\end{array}$ & $\begin{array}{l}\text { Menambah, } \\
\text { dan } \\
\text { menghapus } \\
\text { data } \\
\text { pemesanan }\end{array}$ & $\begin{array}{l}\text { Input: Data } \\
\text { pemesanan, dan } \\
\text { jadwal } \\
\text { Output: Data } \\
\text { Pemesanan }\end{array}$ & Admin \\
\hline 5 & $\begin{array}{l}\text { Pemesanan } \\
\text { Ruangan }\end{array}$ & $\begin{array}{l}\text { Menampilkan } \\
\text { Form } \\
\text { Pemesanan }\end{array}$ & $\begin{array}{l}\text { Input: Data } \\
\text { pemesanan, dan } \\
\text { jadwal } \\
\text { Output: Data } \\
\text { Pemesanan }\end{array}$ & $\begin{array}{l}\text { Admin atau } \\
\text { Pemesan }\end{array}$ \\
\hline 6 & Melihat Ruangan & $\begin{array}{l}\text { Menampilkan } \\
\text { data ruangan }\end{array}$ & $\begin{array}{l}\text { Output: Data } \\
\text { Ruangan }\end{array}$ & $\begin{array}{l}\text { Admin atau } \\
\text { Pemesan }\end{array}$ \\
\hline 7 & Melihat Jadwal & $\begin{array}{l}\text { Menampilkan } \\
\text { data jadwal }\end{array}$ & $\begin{array}{l}\text { Output: Data } \\
\text { Jadwal }\end{array}$ & $\begin{array}{l}\text { Admin atau } \\
\text { Pemesan }\end{array}$ \\
\hline 8 & $\begin{array}{l}\text { Melihat } \\
\text { Laporan }\end{array}$ & $\begin{array}{l}\text { Menampilkan } \\
\text { Data Laporan }\end{array}$ & $\begin{array}{l}\text { Output: Data } \\
\text { Laporan }\end{array}$ & $\begin{array}{l}\text { Admin, } \\
\text { Pemesan } \\
\text { atau HRD }\end{array}$ \\
\hline 9 & Login & $\begin{array}{lr}\text { Login } & \text { ke } \\
\text { dalam } & \text { sistem } \\
\text { dengan } & \\
\text { username dan } \\
\text { password }\end{array}$ & $\begin{array}{l}\text { Input: Username, } \\
\text { password }\end{array}$ & $\begin{array}{l}\text { Admin, } \\
\text { Pemesan } \\
\text { atau HRD }\end{array}$ \\
\hline
\end{tabular}




\section{Class Diagram}

Class Diagram mendeskripsikan jenis-jenis objek dalam sistem dan hubungan antar table yang terjadi. Pada Sistem Informasi Pemesanan Ruangan Meeting berbasis Web Pada PT. Barata Indonesia terdapat lima class utama yang dibangun yaitu room, time, schedule, booking dan user. Yang dapat dilihat dengan gambar sebagai berikut:

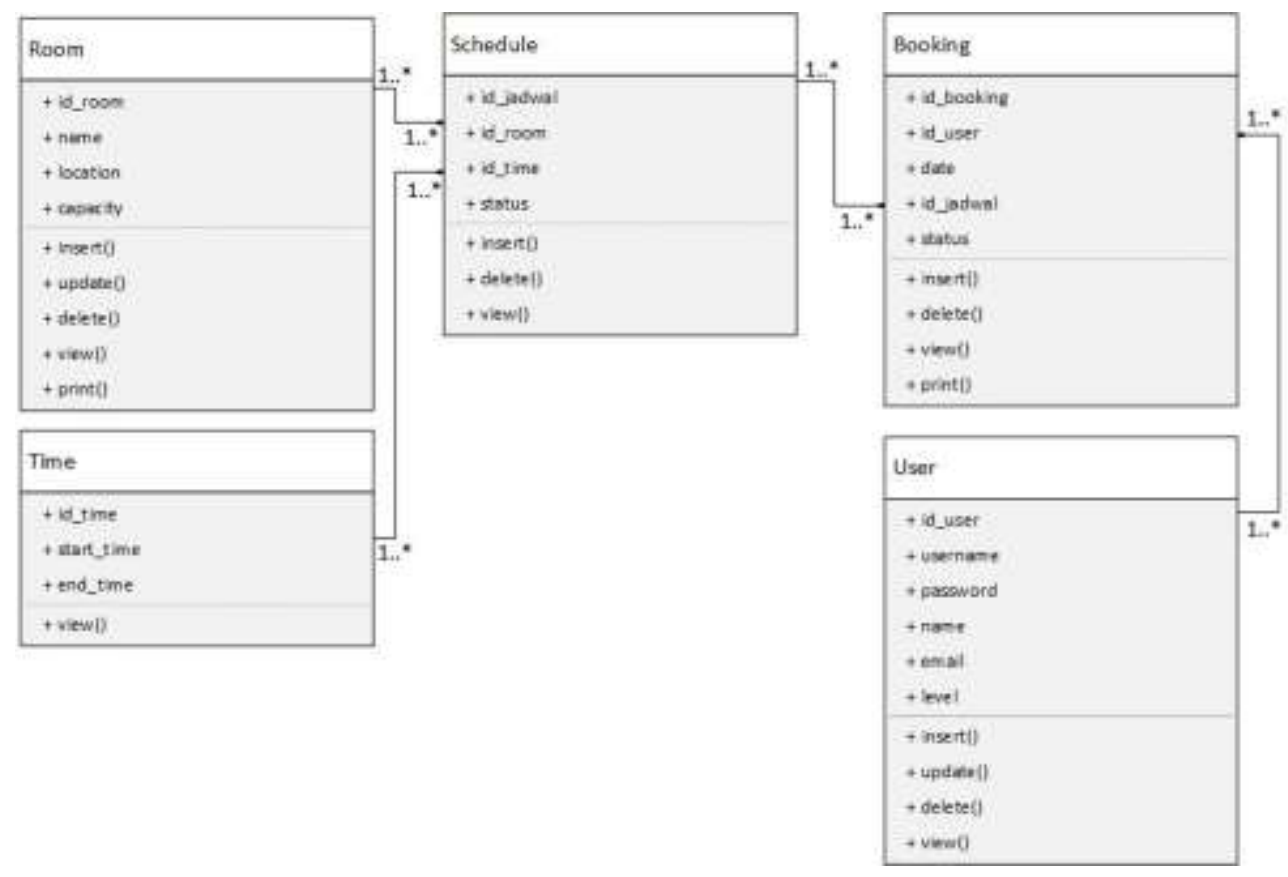

Gambar 4. Class Diagram

\section{Activity Diagram}

Pada Sistem Pemesanan Ruangan Meeting berbasis Web pada PT. Barata Indonesia terdapat beberapa activity diagram yaitu sebagai berikut: 
a. Activity Diagram Login

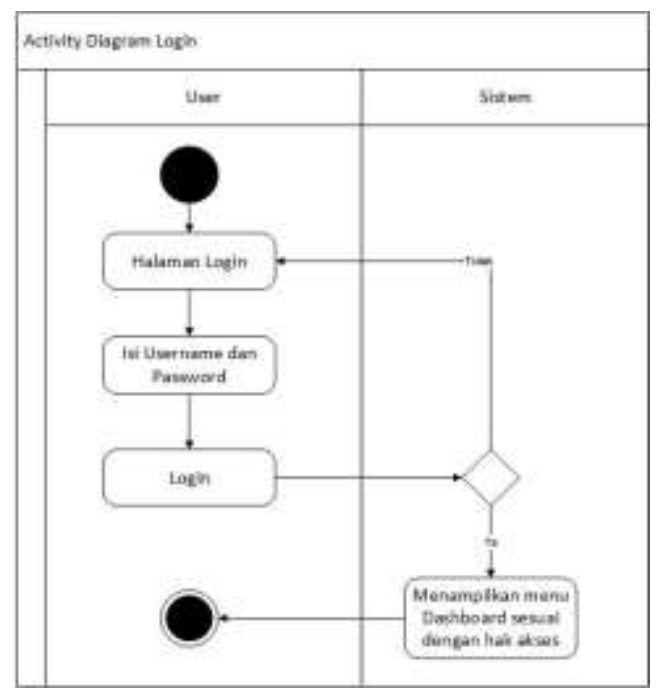

Gambar 5. Aktivity Login

Menggambarkan jalur kerja sistem pada saat pertama kali user menjalankan sistem, yang mengharuskan login terlebih dahulu dengan mengisikan username dan password yang telah terdaftar dalam sistem. Yang dimana jika username dan password yang diisikan telah sesuai maka sistem akan menampilkan menu dashboard sesuai dengan level user yang telah login.

b. Activity Diagram Admin

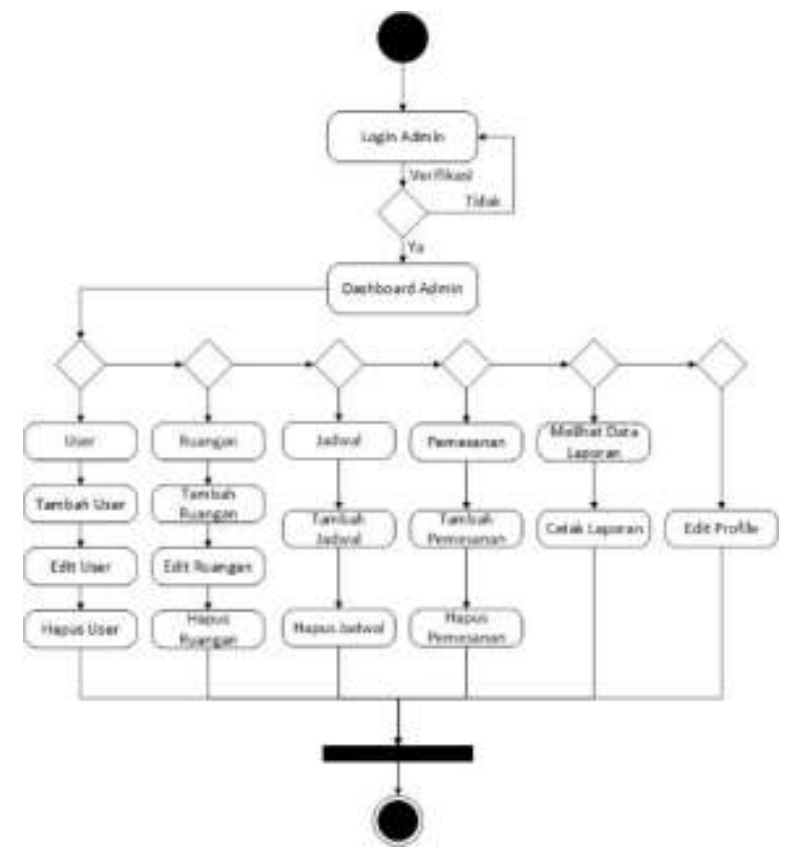

Gambar 6. Aktivity Diagram Admin 
Menjelaskan Tentang bagaimana sistem berjalan yang terdapat pada menu dan hak ases admin pada sistem. Yang dimana admin dapat mengubah, mengedit dan menghapus hingga dapat mengelola keseluruhan menu yang ada pada sistem.

c. Activity Diagram Pemesan

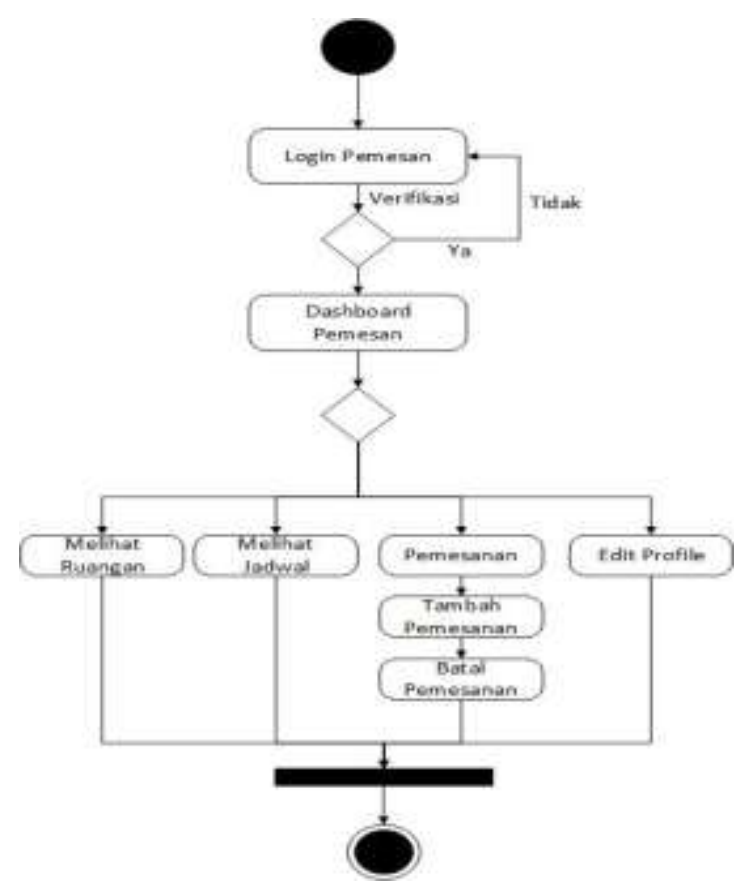

Gambar 7. Aktivity Diagram Pemesanan

Menjelaskan menu dan hak ases yang tersedia untuk login sebagai pemesan, dimana pemesan dapat melihat data ruangan, data jadwal, melakukan pemesanan, serta mengubah profil. 
d. Activity diagram HRD

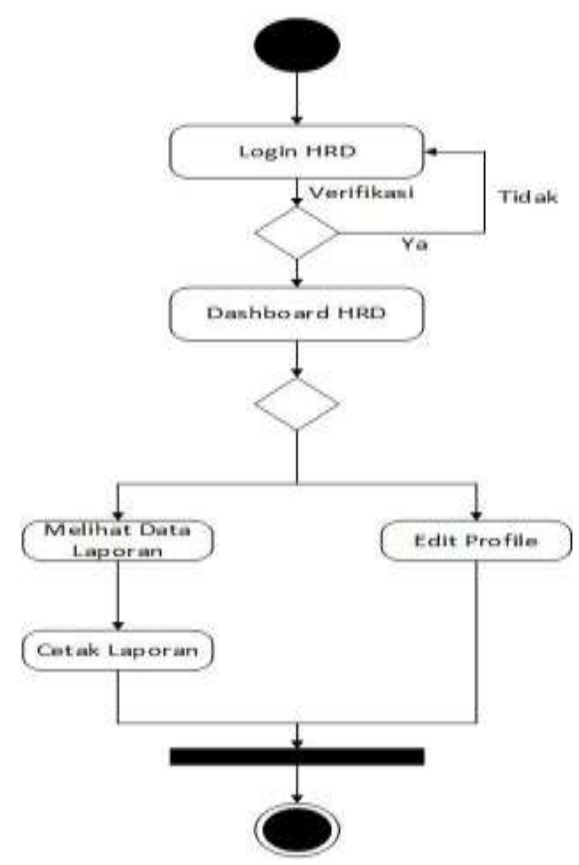

Gambar 8. Aktivity Diagram HRD

Menjelaskan menu dan hak ases yang tersedia untuk login sebagai HRD, dimana HRD dapat melihat, mencetak data laporan, serta mengubah profil.

\section{Sequence Diagram}

Menggambarkan interaksi antara sejumlah objek dalam urutan waktu. Kegunaanya untuk menunjukan rangkaian pesan yang dikirim antara objek sebagai interaksi antar objek yang terjadi pada titik tertentu dalam eksekusi yang ada pada sistem informasi pemesanan ruangan meeting berbasis web pada PT Barata Indonesia terdapat beberapa sequence diagram, diantaranya sebagai berikut: 
a. Sequence Diagram Login

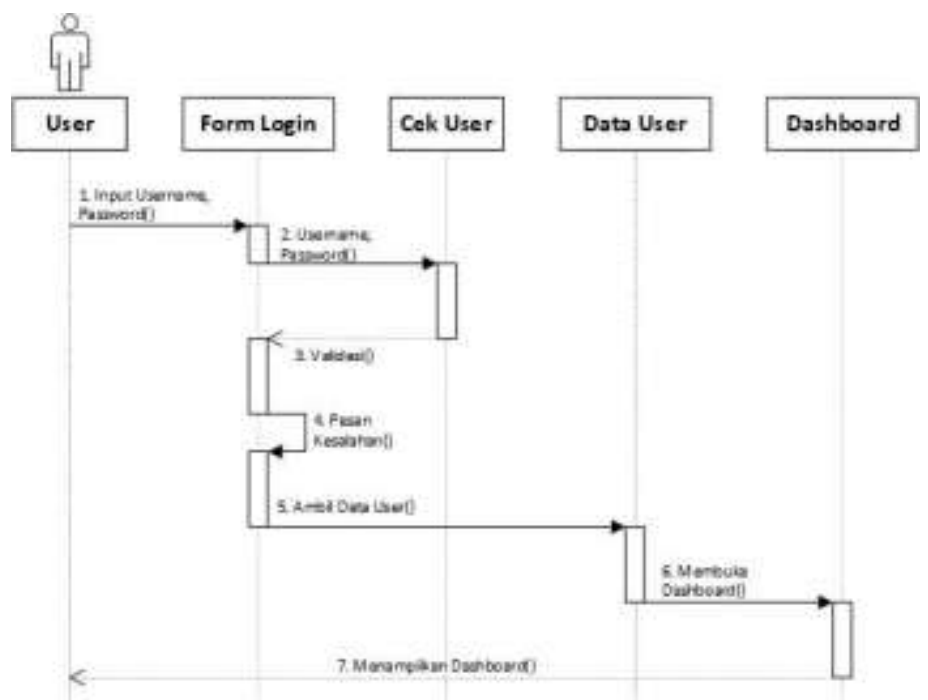

Gambar 9. Sequence Diagram Login

Menjelaskan alur ketika user melakukan login. Dimana user memasukan username dan password pada form login, kemudian sistem akan mengecek, dan jika data yang dimasukan benar maka sistem akan mengambil data user dan akan diteruskan ke menu dashboard sesuai level yang telah login.

b. Sequence Diagram Pemesanan

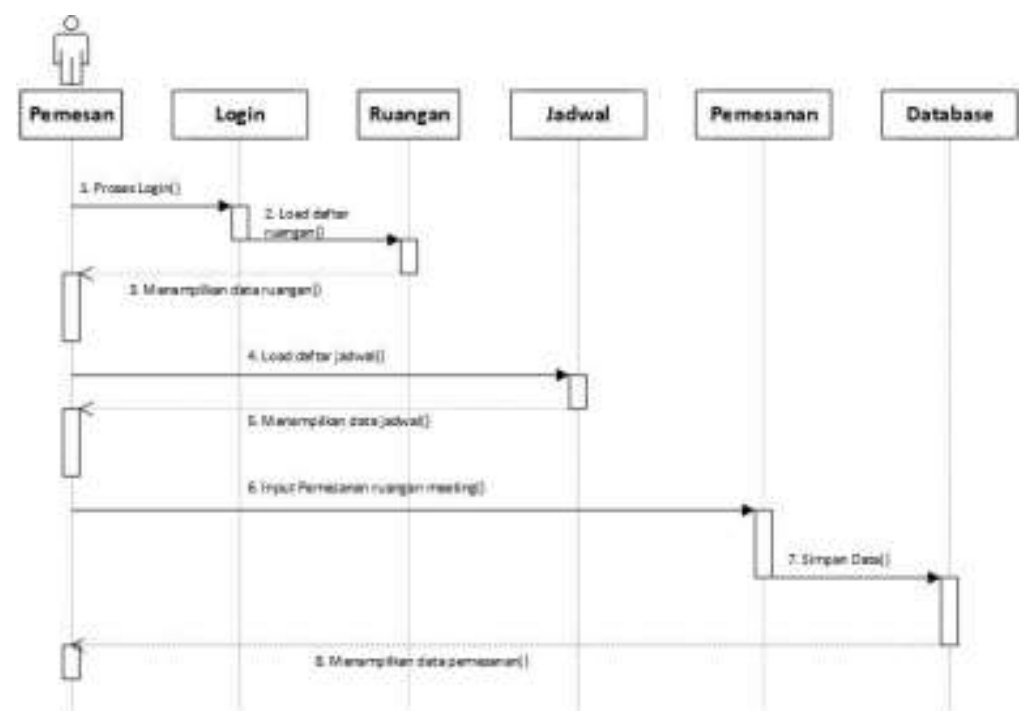

Gambar 10. Sequence Diagram Pemesanan 
Menjelaskan alur ketika user melakukan pemesanan, yang dimulai dengan user login kedalam sistem, kemudian user melihat jadwal ruangan yang ingin dipesan, maka sistem akan menampilkan jadwal ruangan yang ingin dipesan dan menampilkanya kepada user. Setelah itu user memesan ruangan yang diinginkannya dengan menginput jadwal dan ruangan yang kemudian dipesan oleh user.

c. Sequence Diagram Batal Pemesanan

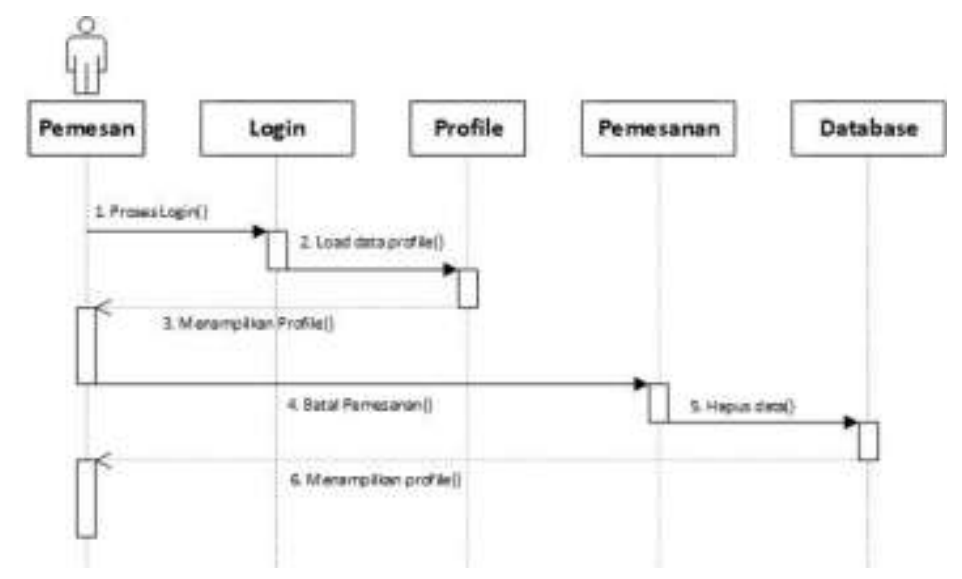

Gambar 11. Sequence Diagram Batal Pemesanan

Menjelaskan alur ketika user melakukan batal pemesanan, yang dimulai Dengan user login kedalam sistem, kemudian user masuk ke menu profile untuk melakukan batal pemesanan ruangan dengan cara klik button batal yang sudah tersedia.

d. Sequence Diagram Cetak Laporan

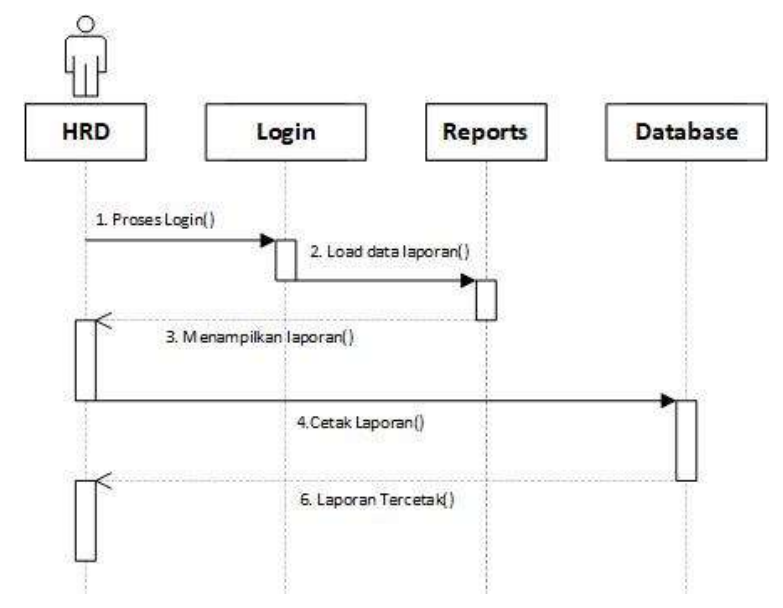

Gambar 12. Sequence Diagram Cetak Laporan 
Menjelaskan alur ketika user melakukan cetak laporan, yang dimulai Dengan user login kedalam sistem, kemudian user masuk ke menu report untuk mencari laporan yang diinginkan, kemudian cetak atau simpan sebagai file PDF.

\section{HASIL IMPLEMENTASI SISTEM}

A. Halaman Login

Sebelum masuk pada halaman dashboard, user diharuskan melakukan login terlebih dahulu agar bisa mengakses aplikasi ini

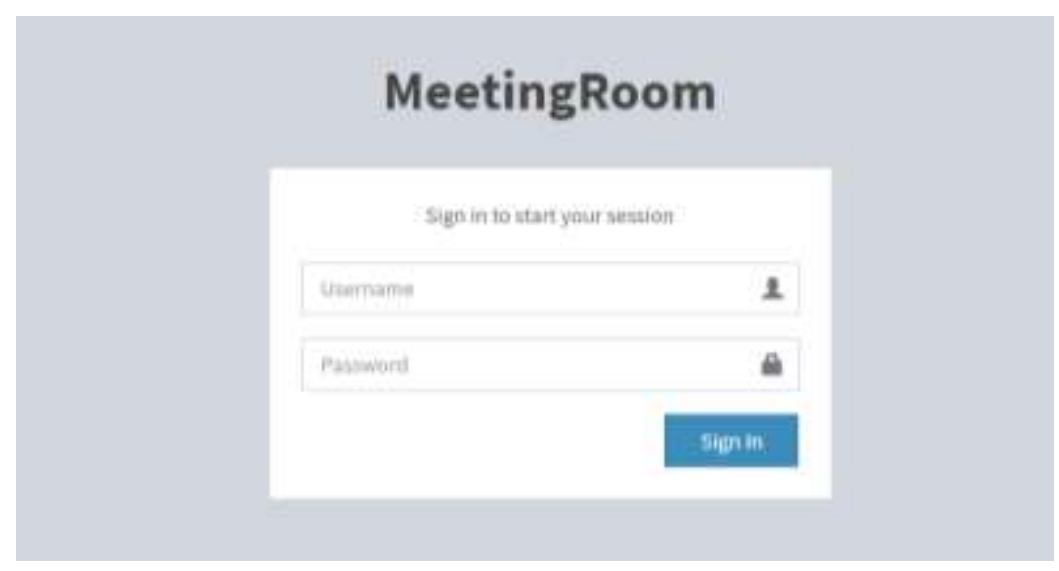

Gambar 13. Halaman Login

B. Halaman Dashboard

Berikut merupakan form tampilan utama dari Aplikasi Pemesanan Ruangan Meeting, menu dashboard akan ditampilkan sesuai level yang akan login.

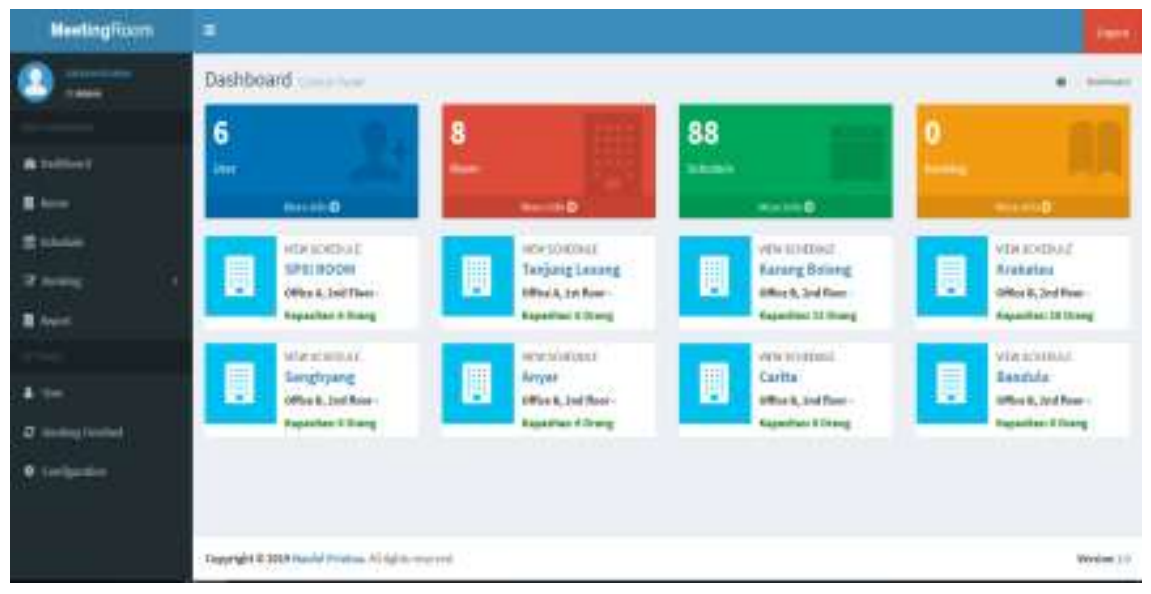

Gambar 14 Halaman Dashboard 
C. Halaman Data Schedule (Jadwal )

Berikut merupakan tampilan menu data schedule, terdapat beberapa fitur untuk menambahkan, mengubah, dan menghapus.

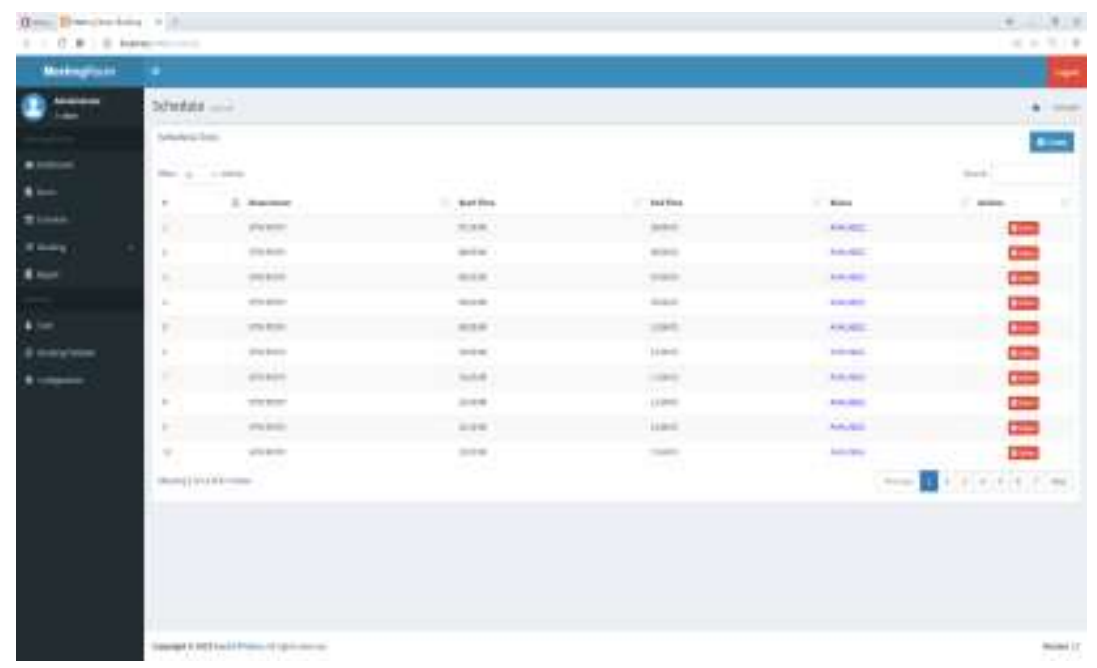

Gambar 15 Halaman Jadwal

D. Halaman Booking (Pemesanan)

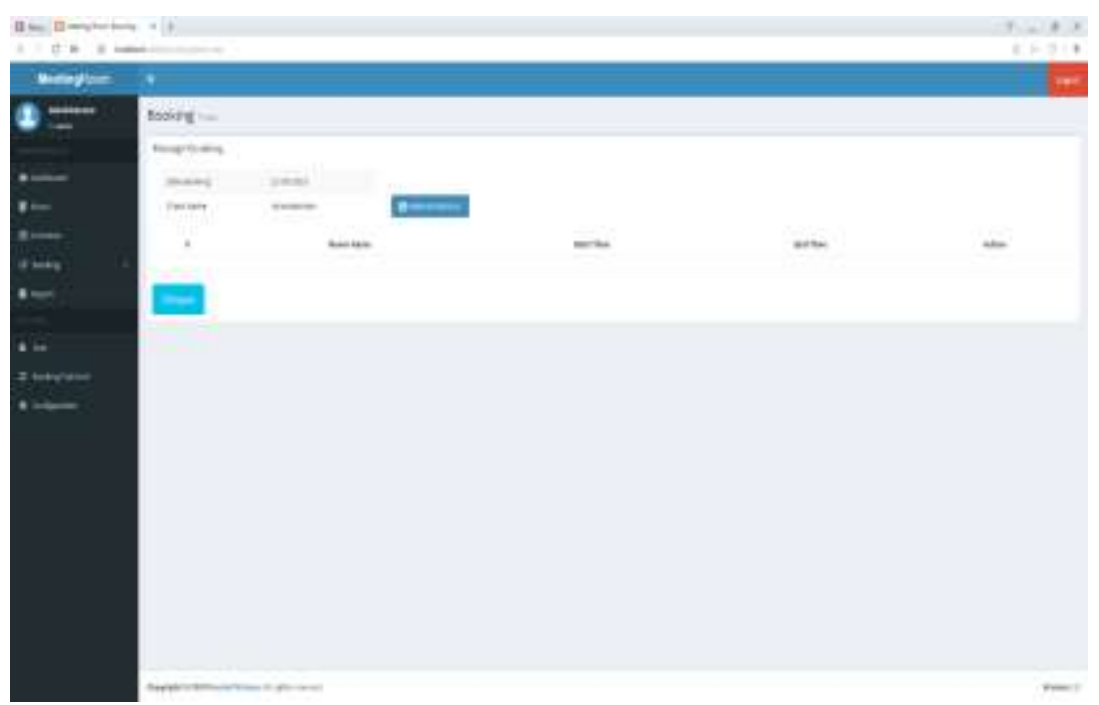

Gambar 16 Halaman Pemesanan 
E. Halaman Report (Laporan)

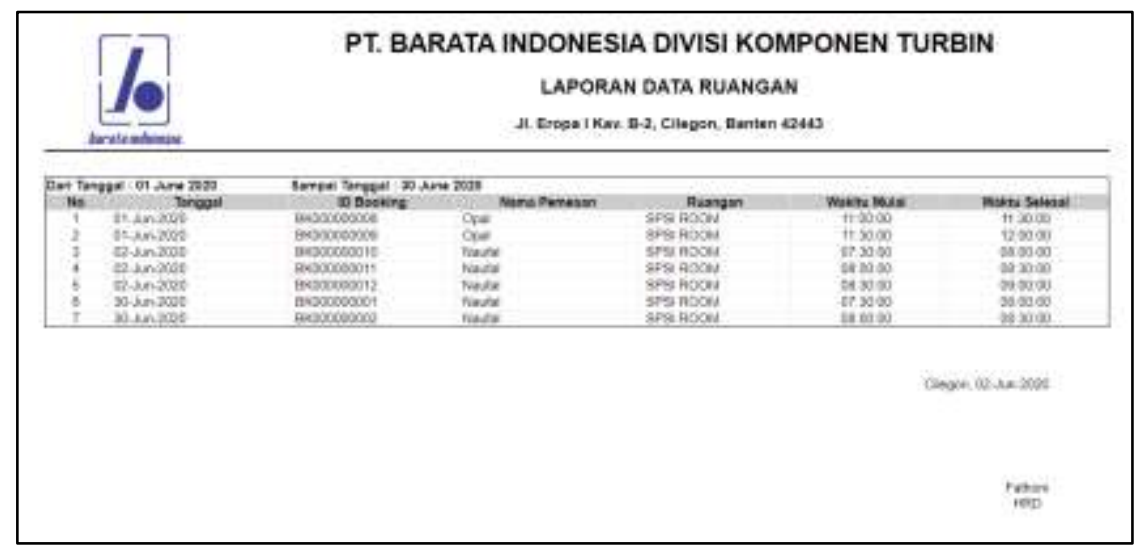

Gambar 17 Laporan

\section{KESIMPULAN}

Berdasarkan hasil penelitian pada sistem pemesanan ruangan meeting di PT Barata Indonesia yang didapat maka dapat disimpulkan bahwa :

1. Proses pelaksanaan pemesanan ruangan meeting di PT Barata Indonesia secara manual yaitu dengan cara pemesan masih harus menanyakan ketersediaan ruangan yang akan dipesan kepada admin untuk mengecek apakah ruangan sedang tersedia atau tidak.

2. Proses pelaksanaan pemesanan ruangan meeting di PT Barata Indonesia secara komputerisasi yaitu dari pemesan tidak harus lagi menanyakan ketersediaan ruangan kepada admin, karena sudah tersedianya sistem monitoring pemesanan ruangan meeting yang dimana informasi dari ketersediaan ruangan dapat langsung diketahui oleh pemesan dan pemesanan lebih mudah dan cepat dibandingkan dengan cara manual.

3. Usaha yang dilakukan untuk mengatasi hambatan yang dialami yaitu melakukan beberapa strategi dalam menulis tugas akhir dengan cara mendisukisan bersama dengan peneliti lainya untuk membantu kelancaran pembuatan tugas akhir yang akan dibuat dan mencari sumber referensi atau sumber pustaka yang cukup. 


\section{REFERENSI}

Anggraeni, Elisabet Yunaeti dan Irviani, Rita. (2017). Pengantar Sistem Informasi. Yogyakarta: Andi Offset.

Firdaus dan Saputra, Ade. (2018). Sistem Informasi Manajemen Pendistribusian Barang Bekas Pada UD. Yuli Mutiara Dengan Bahasa Pemograman PHP Dan Database MySQL. Vol. 25, No. 2, 180-188.

Fridayanthie, Eka Wida dan Mahdiati, Tias. (2016). Rancang Bangun Sistem Informasi Permintaan ATK Berbasis Intranet. Jurnal Khatulistiwa Informatika, Vol. 4, No. 2, 130.

Hakim, dkk. 2019. Sistem Informasi Pemesanan Barang Berbasis Web Pada CV Cipta Karya Mandir. Jurnal Sisfotek Global. Vol. 9. No. 2.

Heriyanto, Yunahar. (2018). Perancangan Sistem Informasi Rental Mobil Berbasis Web Pada PT. Apm Rent Car. Jurnal Intra-Tech. Vol. 2. No. 2. 69.

Herlina, Asti dan Rasyid, Prima Muhammad. (2016). Sistem Informasi Monitoring Pengembangan Software Pada Tahap Development Berbasis Web. Jurnal Informatika, vol. 3, no. 1.

Kurniawan, Aldo, dkk. (2019). Perancangan Sistem Pengolahan Laporan Data Gaji Guru Basiskan Desktop pada Sekolah SDN 06 guguk Sarai Kab. Solok dengan Menerapkan Bahasa Pemrograman Java Dan Dartabase MySQL. Jurnal Ekobistek, Vol. 1, No. 1, 3.

Latifahul, Ryan, dkk. 2018. Sistem Informasi Pelayanan Kesehatan Online Berbasis Web Pada PMI Kabupaten Purbalingga. Jurnal Evolusi. Vol. 6. No. 2. 7 .

Nugraha, Andaopi Rizky, dkk. (2019). Aplikasi Pengelolaan Umkm Dan Pemasaran Produk Umkm Berbasis Web. e-Proceeding of Applied Science, Vol. 5, No. 2, 1176.

Rahardja, Untung. dkk. (2016). Optimalisasi Viewboard Rhjfox Berbasis Bootsrap Sebagai sistem Penunjang Keputusan. Technomedia Journal. Vol. 1. No.1 Edisi Agustus. 62.

Raharjo, Budi. (2018). Belajar Otodidak Framework Codeigniter. Edisi Revisi, Bandung: Informatika, 5-88.

Rahdiansyah, Mochamad. (2019). Pengembangan Sistem Informasi Pengolahan Data Produksi Penerbangan Overflying Pada Perum Lppnpi Kantor Cabang Jatsc. Tangerang: STMIK Raharja.

Rosa A.S dan Shalahuddin, M.. (2018). Rekayasa Perangkat Lunak Terstruktur dan Berorientasi Objek. Edisi Revisi, Bandung: Informatika. 
Rotmianto, Mohamad. (2016). Pengembangan Plugin e-DDC sebagai Aplikasi Tambahan oada Senayan Library Management System Menggunakan Bahasa Pemrograman PHP dan Database. Vol. 2. No. 1. 21.

Sidik, Achmad, dkk. (2019). Perancangan Sistem Informasi Pengolahan dan Dokumentasi Ijazah Pada SDS Penabur Ilmu Tangerang. Vol. 9, No. 1.

Wajhillah, Rusda dan Mutiara, Erika. (2016). Penerapan Algoritma C4.5 Untuk Diagnosa Status Gizi Pada Anak Balita Berbasis Website. Jurnal Sistem Informasi. vol. 4, no. 2. 179.

Yogaswara, Arrad dan Kusnawi. (20160. Sistem Reservasi Tiket Online Pada Museum Batik Yogyakarta Berbasis Web. Yogyakarta: STIKOM AMIKOM, 2016, 2.

Yulia dan Fauzi, Rahmat. (2018). Sistem Informasi Manajemen. Batam: UPB.

Yuliana, Khozin, dkk. (2019). Perancangan Rekapitulasi Pengiriman Barang Berbasis Web. Jurnal Sisfotek Global. Vol. 9. No. 1.

Yuniasari, Intan. (2019). Perancangan Model Reservasi Layanan Tamu di Salon Anata. Bandung: UPB.

Zakir, Ahmad. (2016). Rancang Bangun Responsive Web Layout Dengan Menggunakan Bootstrap Framework, Jurnal Nasional Informatika dan Teknologi Jaringan, Vol. 1, No. 1, 7. 